\title{
Origin of the $\mathrm{X}$-chromosome influences the development and treatment outcomes of Turner syndrome
}

\author{
Ying Zhang ${ }^{1}$, Yong-chen Yang ${ }^{2}$, Pin $\mathrm{Li}^{1}$, Sheng Guo ${ }^{\text {Corresp. } 1}$ \\ ${ }^{1}$ Department of Endocrinology, Shanghai Children's Hospital, Shanghai Jiaotong University, Shanghai, Shanghai, China \\ 2 Department of Laboratory Medicine, Shanghai Children's Hospital, Shanghai Jiaotong University, Shanghai, Shanghai, China \\ Corresponding Author: Sheng Guo \\ Email address: guosheng@shchildren.com
}

Turner syndrome (TS) affects 1/2500 live-born female infants. In the present study, we attempted to clarify the relationship between genetic factors (especially the Xchromosome origin), clinical features, body/sexual development, and treatment outcomes. We enrolled 39 female infants aged between 3 and 14 years. General demographic and clinical features were documented, and laboratory analysis of blood samples was performed. Subject karyotype was determined by G-banding of 50 peripheral white blood cells, and the parenteral origin of the retained X-chromosome was determined. Next, growth hormone $(\mathrm{GH})$ treatment was prescribed for 12 months, with follow-ups performed as determined. For patient groups separated according to X-chromosome origin, the basal height, bone age, insulin-like growth factor (IGF)-1, and insulin-like growth factor binding protein-3 (IGFBP-3) levels were comparable; however, after the 12-month treatment, significant differences in the height increase and IGF-1 levels were observed. If the Xchromosome (or chromosomes) originated from both parents, the increase in height was less substantial, with lower serum IGF-1 levels. The uterine size, prolactin level, increased weight after treatment, and bone age difference after treatment negatively correlated with the mother's age at the time of birth. The mother's height at the time of birth demonstrated a negative correlation with the basal bone age difference and a positive correlation with the IGF-1 level. In summary, the retained X-chromosome derived from both parents is associated with poorer response to GH therapy. The mother's age and height at the time of birth can strongly impact the patient's body/sexual development and the response to GH treatment. Thus, the mother's age and height at the time of birth and the parental origin of the X-chromosome should be carefully considered before developing a treatment plan for TS. 
1 Origin of the $\mathrm{X}$-chromosome influences the development and treatment outcomes of Turner

2 syndrome

3 Running Title: X origin influences Turner syndrome treatment

4 Ying Zhang, $M S^{1}$, Yong-chen Yang, $M S^{2}$, Pin Li, MS ${ }^{1}$, Sheng Guo, $M D^{1, *}$

$5{ }^{1}$ Department of Endocrinology, Shanghai Children's Hospital, Shanghai Jiaotong University, No. 355,

6 Luding Road, Putuo District, Shanghai, 200062, China,

$7 \quad 2$ Department of Laboratory Medicine, Shanghai Children's Hospital, Shanghai Jiaotong University, No.

8 355, Luding Road, Putuo District, Shanghai, 200062, China.

9

$10 *$ Correspondence to:

11 Sheng Guo

12 Department of Endocrinology, Shanghai Children's Hospital, Shanghai Jiaotong University, No. 355,

13 Luding Road, Putuo District, Shanghai, 200062, China.

14 Tel./Fax: +86-021-62474880

15 Email: guosheng@shchildren.com 
16 ABSTRACT

17 Turner syndrome (TS) affects 1/2500 live-born female infants. In the present study, we attempted to

18 clarify the relationship between genetic factors (especially the X-chromosome origin), clinical features,

19 body/sexual development, and treatment outcomes. We enrolled 39 female infants aged between 3 and 14

20 years. General demographic and clinical features were documented, and laboratory analysis of blood

21 samples was performed. Subject karyotype was determined by G-banding of 50 peripheral white blood

22 cells, and the parenteral origin of the retained X-chromosome was determined. Next, growth hormone

23 (GH) treatment was prescribed for 12 months, with follow-ups performed as determined. For patient

24 groups separated according to X-chromosome origin, the basal height, bone age, insulin-like growth

25 factor (IGF)-1, and insulin-like growth factor binding protein-3 (IGFBP-3) levels were comparable;

26 however, after the 12-month treatment, significant differences in the height increase and IGF-1 levels

27 were observed. If the X-chromosome (or chromosomes) originated from both parents, the increase in

28 height was less substantial, with lower serum IGF-1 levels. The uterine size, prolactin level, increased

29 weight after treatment, and bone age difference after treatment negatively correlated with the mother's age

30 at the time of birth. The mother's height at the time of birth demonstrated a negative correlation with the

31 basal bone age difference and a positive correlation with the IGF-1 level. In summary, the retained X-

32 chromosome derived from both parents is associated with poorer response to GH therapy. The mother's

33 age and height at the time of birth can strongly impact the patient's body/sexual development and the

34 response to GH treatment. Thus, the mother's age and height at the time of birth and the parental origin of

35 the X-chromosome should be carefully considered before developing a treatment plan for TS.

Peer) reviewing PDF | (2020:11:55731:2:1:NEW 13 Sep 2021) 
36 Keywords: Turner syndrome, X-chromosome origin, IGF-1. 


\section{INTRODUCTION}

38 Turner syndrome (TS) is a common chromosomal disorder caused by the loss of all or a significant part of

39 one X-chromosome in a phenotypic female, usually presenting with short stature and premature ovarian

40 failure. This condition affects approximately $1 / 2500$ live-born female infants. Previous studies have

41 described the cytogenetic characterization of patients with TS (Chauhan et al., 2016; Burégio-Frota et al.,

42 2010; Moka et al., 2013), with a majority of published reports focusing on karyotype-phenotype

43 associations (Noordman et al., 2019; Cameron-Pimblett et al., 2017; Aversa et al., 2015; Verver et al.,

44 2014; Verver et al., 2011). For example, a study assessing karyotype features associated with TS-specific

45 hearing loss has revealed that elevated air conduction thresholds can be associated with loss of the $\mathrm{p}$ arm

46 of chromosome X (King et al., 2007). In contrast, monosomy karyotype (45, X) has been associated with

47 a more severe, lymphatic, and skeletal phenotype of dysmorphic features and cardio-aortic malformations

48 (Noordman et al., 2018). The clinical features of TS largely depend on the involved regions of the X-

49 chromosome. These X-structural abnormalities include deletions, duplications, isochromosomes of the

50 long arm, isodicentric chromosomes, complex abnormalities with combined deletions and duplications,

51 inversions, rings, and translocations. Typically, around 40\%-50\% of patients exhibit monosomy (45, X),

52 around $10 \%$ of patients are diagnosed with mosaicism $(45, \mathrm{X}) /(46, \mathrm{XX})$, approximately $20 \%$ of patients

53 have karyotype with isochromosomes, and nearly 20\% present other karyotypes (Noordman et al., 2019;

54 King et al., 2007; Noordman et al., 2018; Ko et al., 2010; Alvarez-Nava et al., 2013). Theoretically,

55 different karyotypes could influence phenotypes during body development, as well as impact treatment

56 outcomes; however, studies investigating these aspects remain limited. Known risk factors associated

Peer) reviewing PDF | (2020:11:55731:2:1:NEW 13 Sep 2021) 
with development and treatment outcomes predominantly include elevated blood pressure in childhood, mid-parental height (MPH), and genetic factors (e.g., the SHOX deficiency phenotype)(Nathwani et al., 2000; Scalco et al., 2019; Jung et al., 2000; Child et al., 2015). Theoretically, some potential predictors are worth investigating, including prolactin, mother's age, and height at the time of birth, and parental origin of the X-chromosome. The parental origin of the $\mathrm{X}$ chromosome may impact the disease onset in terms of different aspects (e.g., aortic stiffness) (Binkert et al., 2010; Yeh et al., 2017; Zeng et al., 2014).

There have been very few studies investigating the influence of parental origin on treatment results, and the controversy regarding the impact of the retained X-chromosome on clinical features persists. In the present study, we attempted to clarify the relationship between genetic factors (especially the X origin), clinical features, body/sexual development, and treatment outcomes in TS. For the first time, we observed some novel links between the $\mathrm{X}$ origin and growth hormone (GH) therapy outcomes, as well as an impact of maternal genetic factors on body/sexual development and GH responses.

\section{MATERIALS AND METHODS}

\section{Patients}

Female children who visited the examination center from January 2019 to April 2020 were selected, and those diagnosed with TS were enrolled. All recruited patients provided signed informed consent. The inclusion criteria for TS children were as follow: (1) females, aged between 3 and 14 years old, (2) diagnosed with TS according to chromosome examination results, (3) who had received GH treatment. TS was diagnosed by lymphocyte chromosomal analysis, in combination with an analysis of clinical features. 
77 None of the subjects had received GH therapy or anabolic steroids previously. Potentially relevant

78 demographic data were recorded, including age, weight, height, father's age at birth, mother's age at birth,

79 father's height at birth, and mother's height at birth. Abnormalities in uterine and ovary size

80 (small/normal/large) were recorded according to previously reported standards(Cohen et al., 1993; Cohen

81 et al., 1990; Orsini et al., 1984).

\section{Laboratory analysis}

For each subject, whole blood samples from an antecubital vein were collected and immediately

centrifuged. The serum was stored or sent to the laboratory within $3 \mathrm{~h}$. Subsequently, the following serum

biochemical indicators were measured using the enzymatic method: GH level, GH excitation peak,

alanine aminotransferase (ALT), aspartate aminotransferase (AST), total cholesterol, high density

lipoprotein (HDL), low density lipoprotein (LDL), insulin, Free T3, Free T4, triiodothyronine, thyroxine,

thyroid-stimulating hormone (TSH), insulin-like growth factor (IGF)-1, insulin-like growth factor binding

protein-3 (IGFBP-3), luteinizing hormone (LH), follicle-stimulating hormone (FSH), estradiol (E2),

91 prolactin, progesterone, human chorionic gonadotropin (HCG), and sex hormone-binding globulin

92 (SHBG).

\section{Parental origin of the $\mathrm{X}$-chromosome using $\mathrm{X}$-chromosome short tandem repeats analysis}

95 We performed chromosome karyotype analysis and microsatellite analysis for each patient to jointly infer

96 the parental origin of the X-chromosome. Karyotype analysis is a classic technique for detecting

97 abnormal chromosome numbers, large fragment copy number variation, and chromosome fusion. We 
used chromosome G-banding technology to analyze 550 bands of chromosomes; microsatellite analysis was then performed for each patient and the parents. The karyotype analysis of chromosomes demonstrates good consistency with the microsatellite analysis. Fluorescence in situ hybridization using $\mathrm{X}$ - and Y-specific $\alpha$ satellite DNA probes was used to characterize marker-chromosomes and ringchromosomes. To analyze the influence of different karyotype groups, the following types were defined: (1) Type-1: 45, X (all cells had karyotype 45, X); (2) Type-2: 46, Xdel (X); (3) Type-3: both 46, Xdel $(\mathrm{X})(\mathrm{q})$ or $46, \mathrm{Xdel}(\mathrm{X})(\mathrm{q})$ and $45, \mathrm{X}$; (4) Type-4: other types. We excluded the karyotype with $\mathrm{Y}$ chromosomes. In all samples, the fragmented X-chromosome was present in 20 to $100 \%$ of white blood cells. The parental origin of the X-chromosome was determined by detecting 9 X-chromosome short tandem repeat (X-STR) loci on the X-chromosome (GATA172D05, DXS10159, DXS6797, HPRTB, DXS10079, DXS6789, DXS9895, DXS10146, and GATA31E08), which are highly polymorphic in the Han population (Huang et al., 2015); their positions on the X-chromosome were q23.00, c, q22.30, q26.20, q12.00, q21.33, p22.32, q28.00, and q27.10, respectively. Polymerase chain reaction (PCR) amplification of 9 X-STR loci was performed, followed by a comparison of the patient's result versus the mother and the father. The result of the $\mathrm{X}$ origin was documented for further analysis.

\section{GH treatment and follow-up}

All patients received GH therapy for twelve months $(1.5 \mathrm{IU} / \mathrm{d} / \mathrm{kg})$, and the height increase, bone age, and IGF-1 and IGFBP3 levels were examined following treatment. Patients lost during follow-up were excluded. 


\section{Statistical analysis}

120 All categorical data were expressed as frequencies and percentages; continuous data were expressed as

121 the mean \pm standard deviation (SD). SPSS software 25.0 (IBM Corp., Armonk, NY, USA) was used for statistical analysis. The Chi-Square test was used to compare frequencies in different groups, and one-way

123 ANOVA was used to compare continuous data. A $p$-value $<0.05$ was set as the significance level.

\section{Ethics statement}

126 This study was approved by Ethics Review Committee, Children's Hospital of Shanghai/Shanghai Children's Hospital, Shanghai Jiao Tong University (Approval No:

128 2017R027-E04), and we strictly followed the standard of ethics established by the committee.

\section{RESULTS}

\section{Clinical characteristics of included children}

132 A total of 39 patients were enrolled, whose demographic information is presented in Table 1 . The average age was 90.90 months (44-154), the average weight was $20.69 \mathrm{~kg}(12.60-36.50)$, and the average was

134 height was $108.72 \mathrm{~cm}(88.9-131.4)$. The mean age of the patients' fathers at birth was 28.59 years (25-35), and that of mothers was 26.74 years (23-31). The average height of the patients' fathers was $169.41 \mathrm{~cm}$

136 (160-177), and that of mothers was $157.59 \mathrm{~cm}$ (152-165). Blood biochemical indicators for enrolled

137 patients are presented in Table 2. Overall, patients had relatively low GH, free T4, prolactin, and 138 progesterone levels. 
139 The genotypes of chromosomes were as follows: $38.5 \%$ (15 cases) children showed a type-1 chromosome

140 category, $10.3 \%$ ( 4 cases) belonged to type- $2,43.6 \%$ (17 cases) were the type- 3 chromosome category,

141 and $7.7 \%$ (3 cases) belonged to type-4. Based on the parenteral chromosome examination, the X-

142 chromosome(s) origins were classified into three categories: from father, from mother, and from both.

143 Overall, $15.4 \%$ (6 cases) had X chromosomes from the father, $41.0 \%$ (16 cases) had X chromosomes

144 from the mother, and 43.6\% (17 cases) had X chromosomes from both.

\section{Association between $\mathrm{X}$ origin and treatment effects}

147 Firstly, we observed the association between the $\mathrm{X}$ origin and treatment outcomes. According to the 148 retained X-chromosome origin (father, mother, or both), all patients were divided into three groups. The 149 basal height, bone age, and IGF-1 and IGFBP3 levels were comparable between groups; however, 150 significant differences in the height increase (HI) $(\mathrm{p}<0.001)$ and IGF-1 levels $(\mathrm{p}<0.001)$ were observed

151 following GH therapy (Table 3). If the X-chromosome (or chromosomes) was/were derived from both

152 parents, the HI and serum IGF-1 levels were lower than those observed in any parent. Furthermore, the 153 age range of subjects enrolled in this study varied widely. To avoid the impact of age on HI, we used age154 matched samples to ensure that only those subjects whose age was within the $90.90 \pm 28.99$ range of total 155 samples were selected. In this set, the results were highly consistent with the total samples (Table 3).

156 These findings indicated more significant challenges in treating those patients who present chromosome 157 disorders from both parents. 
160 Theoretically, maternal genetic factors have a greater impact on child development and GH treatment.

161 Among the basal clinical characteristics, uterine size, and prolactin level both negatively correlated with

162 the mother's age at birth of the subject $(\mathrm{p}<0.01)$ (Table 4). For prolactin, the relevance was above $0.5(-$

163 0.508), with a high significance $(\mathrm{p}=0.001)$. Following GH therapy, the weight increase and bone age

164 difference negatively correlated with the mother's age at birth of the subject $(\mathrm{p}<0.05)$. These results may

165 suggest that an elder pregnant woman may bear a TS child with a poor status and more significant

treatment challenges. Moreover, the mother's height at the subject's birth may impact development and

GH treatment. Accordingly, the basal bone age difference was negatively associated with the mother's

height $(\mathrm{R}=-0.336, \mathrm{p}=0.036)$, while the IGF-1 level after treatment was positively correlated with the

mother's height $(\mathrm{R}=0.388, \mathrm{p}=0.015)$. However, these relationships have not been observed in paternal

genetic factors.

\section{DISCUSSION}

TS is typically caused by karyotype variations, but it can also be heritable according to some typical case

reports (Ramachandram et al., 2013; Periquito et al., 2016). GH therapy is the most widely used strategy,

apart from estrogen and oxandrolone therapies. This treatment can effectively improve the bone mineral density and body height in patients with TS (Wasniewska et al., 2013; Soucek et al., 2011; Menke et al.,

2010; Bannink et al., 2009; Spiliotis 2008; Morin et al., 2009; Lanes et al., 2019). In particular, the GH-

178 IGF-IGFBP axis is altered in TS (Gravholt et al., 2006); long-term GH treatment can restore IGF-1 and

179 IGFBP-3 levels, which are valuable indicators of treatment outcomes (Pankowska et al., 2007; Baş et al., 
180

2012; Bautembach-Minkowska et al., 2018; Blanco-López et al., 2020). Notably, IGF-I has been considered a marker of growth response (Darendeliler et al., 2007). Moreover, some laboratory indicators are potentially relevant to TS, e.g., prolactin, as implied by previous reports; hence, we included several candidate factors in laboratory analysis(Amendt et al., 1992; Salvarci et al., 2018; Yeh et al., 2017). In the present study, we performed a follow-up survey, mainly focusing on changes in height, body weight, IGF-1, IGFBP-3, and bone age.

Generally, the TS karyotype can be classified into four types: monosomy, mosaic, variant, and mosaic with variant $(W u \& L i, 2019)$. Monosomy $45, \mathrm{X}$ has been detected in approximately $45 \%-50 \%$ of cases, with other patients presenting various chimeras and structural abnormalities (Cui et al., 2018). Theoretically, genetic factors can strongly decide the disease state and treatment outcomes. Growth retardation tends to be more severe in patients with $\mathrm{XrX}$, isoXq, and $(45, \mathrm{X})$ karyotypes than in patients with $(45, \mathrm{X}) /(46, \mathrm{XX})$ karyotypes or a Y chromosome (Fiot et al., 2016). Several studies have assessed the effect of parental origin of the X-chromosome on clinical features, associated complications, and the response to GH therapy. Francisco Álvarez-Nava et al. have shown that parental origin of the retained Xchromosome may influence lipid metabolism in patients with TS, but its effect on growth seems to be minimal (Alvarez-Nava et al., 2013). The authors did not detect any impact on phenotypic features, associated anomalies, or the growth response to GH in $(45, \mathrm{X}) \mathrm{TS}$ individuals. This negative result corroborates the conclusions of Devernay M and Ko JM (Ko et al., 2010; Devernay et al., 2012), although

Kochi $\mathrm{C}$ et al. previously reported a strong influence of genes located on the maternal X-chromosome, particularly on stature (Kochi et al., 2007). To date, the present study is among few research endeavors revealing the impact of X-chromosome origin on GH treatment effects. We noted that when a patient with 
201 TS presents an X-chromosome (or X chromosomes) from both parents, she is more likely to have a lower

202 HI and IGF-1 level; however, no difference was observed in patients with X chromosomes derived from

203 the father or mother. These results suggest that X chromosomes from both parents may induce a less

204 functional loss in growth and development, with a complex etiology, such that single exogenous GH

supplementation may afford only limited effects. Nevertheless, we did not undertake detailed sequencing

and, so far, we are unable to implicate the mechanism underlying the influence of combined variation

sources.

Another unexpected finding is that the mother's age and height at the time of the subject's birth might

strongly influence body development and GH treatment. The clear mechanism is still to be explored. To

our best knowledge, this is the first work showing the correlation between mother's age and height at the

time of the patient's birth and GH treatment response, and no direct evidence was found for reference.

The etiology of this finding can be explained as follow. First, the uterine size was found to be smaller if

the child was born to an older mother, which can be expected. Consistently, the patient's prolactin level

significantly decreased as the mother's age at birth increased. Prolactin ay partially impact the GH

response to growth hormone-releasing hormone (Losa et al., 1988). Besides, elderly women tend to have

chromosomal abnormality of oocyte, which leads to a high incidence rate of fetal chromosomal

abnormality(Ben-Meir et al., 2015; Xu et al., 2018). However, it is still early to recommend for early

childbirth towards mothers of potential TS children. The mother's height at the time of birth positively

correlated with the GH therapy response, as indicated by the IGF-1 level after treatment, suggesting that

patients with TS may benefit from a taller mother; however, the underlying mechanism needs to be

explored. Intriguingly, the bone age difference at the baseline level negatively correlated with the 
222

223

224

225

226

227

228

229

230

231

232

233

234

235

236

237

238

239

240

241

mother's height at the time of birth, with no association observed following treatment. This may be attributed to the following reasons. Firstly, the p-value was not sufficiently small, and our sample size was limited; hence, this conclusion needs to be confirmed with more evidence. Secondly, the mother's increased height may suppress the bone development in the TS child, despite benefits for GH responses. Therefore, a negative correlation was observed at baseline, but the correlation was not observed after treatment. This hypothesis warrants further corroborative investigations.

The present study has some limitations. First, this study was conducted over an extremely brief timeframe (only one year), and the results may therefore not best predict the outcomes. Accordingly, we plan to perform an investigation with a more extended follow-up period. In addition, the age range of subjects varied greatly; this is to be expected, as mildly affected patients are diagnosed late, and presumably, those diagnosed late demonstrate poor growth potential. Their poor height outcome may be due to missed treatment. Our future investigation will accumulate more samples and narrow the age range. Moreover, based on the present findings, our ensuing investigation will focus on a potentially effective strategy for those TS patients with retained X chromosomes derived from both parents, as well as high-risk children with TS sisters.

\section{CONCLUSION}

In summary, the retained X-chromosome derived from both parents weakens the response to GH therapy.

The mother's age and height at the time of birth can impact the patient's body/sexual development and GH treatment outcomes. Based on these data, considerable attention should be paid to analyzing the 
242 mother's age and height at the time of birth, as well as to the parental origin of the X-chromosome, prior

243 to developing an effective treatment plan for TS.

\section{ABBREVIATIONS}

TS, Turner syndrome; GH, growth hormone; ALT, alanine aminotransferase; AST, aspartate aminotransferase; HDL, high density lipoprotein; LDL, low density lipoprotein; TSH, thyroid-stimulating hormone; LH, luteinizing hormone; FSH, follicle-stimulating hormone; HCG, human chorionic gonadotropin; SHBG, sex hormone binding globulin; X-STR, X-chromosome short tandem repeats; SD, standard deviation.

\section{ADDITIONAL INFORMATION AND DECLARATIONS}

Funding

The Fund of the Shanghai Municipal Commission of Health and Family Planning (No. 20174Y0007) and the Key and Special Project of Clinical Research and Cultivation of Shanghai Children's Hospital ( NO 2019YLYM07 )

Competing Interests

The authors declare that they have no competing interests. 
263 Experimental operation, subject design, execution: Ying Zhang

264 Guide: Pin Li and Sheng Guo

265 Experimental operation: Yong-Chen Yang.

266

267

Data Availability

268 The raw data summary is available as a Supplemental File.

\section{REFERENCES}

Aversa T, Messina MF, Mazzanti L, Salerno M, Mussa A, Faienza MF, Scarano E, De Luca F,

Wasniewska M. 2015. The association with Turner syndrome significantly affects the course of Hashimoto's thyroiditis in children, irrespective of karyotype. Endocrine 50(3):777-782. DOI $10.1007 / \mathrm{s} 12020-014-0513-6$

Alvarez-Nava F, Lanes R, Quintero JM, Miras M, Fideleff H, Mericq V, Marcano H, Zabala W, Soto M, Pardo T, Borjas L, Villalobos J, Gunczler P, Unanue N, Tkalenko N, Boyanofsky A, Silvano L, Franchioni L, Llano M, Fideleff G, Azaretzky M, Suarez M. 2013. Effect of the parental origin of the X-chromosome on the clinical features, associated complications, the two-yearresponse to growth hormone (rhGH) and the biochemical profile in patients with turner syndrome. International journal of pediatric endocrinology 2013(1):10. DOI 10.1186/1687-9856-2013-10 
1211138.

Binkert F, Spreiz A, Höckner M, Miny P, von Dach Leu B, Erdel M, Zschocke J, Utermann G,

Kotzot D. 2010. Parental origin and mechanism of formation of a 46, $X, \operatorname{der}(X)($ pter-->q21.1: p11.4->pter)/45, X karyotype in a woman with mild Turner syndrome. Fertility and sterility 94(1): 350 e12-15. DOI 10.1016/j.fertnstert.2009.12.040

Burégio-Frota P, Valença L, Leal GF, Duarte AR, Bispo-Brito AV, Soares-Ventura EM,

Marques-Salles TJ, Nogueira MT, Muniz MT, Silva ML, Hunstig F, Liehr T, Santos N. 2010.

Identification of a de novo inv $\operatorname{dup}(\mathrm{X})($ pter--> q22) by multicolor banding in a girl with Turner syndrome. Genetics and molecular research 9(2):780-784. DOI 10.4238/vol9-2gmr777

Bannink EM, van der Palen RL, Mulder PG, de Muinck Keizer-Schrama SM. 2009. Long-term follow-up of GH-treated girls with Turner syndrome: BMI, blood pressure, body proportions. Hormone research 71(6):336-342. DOI 10.1159/000223418

Baş F, Darendeliler F, Aycan Z, Çetinkaya E, Berberoğlu M, Sıklar Z, Öcal G, Timirci Ö,

Çetinkaya S, Darcan Ş, Gökşen Şimşek D, Bideci A, Cinaz P, Böber E, Demir K, Bereket A, Turan S, Atabek ME, Tütüncüler F, Isbir T, Bozkurt N, Kabataş Eryılmaz S, Uzunhan O,

Küçükemre Aydın B, Bundak R. 2012. The exon 3-deleted/full-length growth hormone receptor polymorphism and response to growth hormone therapy in growth hormone deficiency and Turner syndrome: a multicenter study. Hormone research in pcediatrics 77(2):85-93. DOI $10.1159 / 000335172$ thyroid carcinoma in a patient with Turner syndrome treated with human growth hormone]. Pediatric 
endocrinology, diabetes, and metabolism 2018(3):145-150. DOI 10.5114/pedm.2018.80997

Blanco-López A, Antillón-Ferreira C, Saavedra-Castillo E, Barrientos-Pérez M, Rivero-

Escalante H, Flores-Caloca O, Calzada-León R, Rosas-Guerra CC, Koledova E, Chiquete E,

Ayala-Estrada A. 2020. Adherence to treatment in children with growth hormone deficiency, small

for gestational age and Turner syndrome in Mexico: results of the Easypod connect observational study (ECOS). Journal of endocrinological investigation 43(10):1447-1452. DOI 10.1007/s40618020-01218-4

Casper RF, Jurisicova A. 2015. Coenzyme Q10 restores oocyte mitochondrial function and fertility during reproductive aging. Aging Cell 14(5):887-895. DOI: 10.1111/acel.12368

Chauhan P, Jaiswal SK, Lakhotia AR, Rai AK. 2016. Molecular cytogenetic characterization of two Turner syndrome patients with mosaic ring X chromosome. Journal of assisted reproduction and genetics 33(9): 1161-1168. DOI 10.1007/s10815-016-0761-x endocrinology 87(5):532-538. DOI 10.1111/cen.13394

Cui X, Cui Y, Shi L, Luan J, Zhou X, Han J. 2018. A basic understanding of Turner syndrome: Incidence, complications, diagnosis, and treatment. Intractable \& rare diseases research 7(4):223228. DOI 10.5582/irdr.2017.01056 
Cutler GB Jr, Blum WF. 2015. Radiological Features in Patients with Short Stature Homeobox-

Containing (SHOX) Gene Deficiency and Turner Syndrome before and after 2 Years of GH

Treatment. Hormone research in pcediatrics 84(1):14-25. DOI 10.1159/000381712.

Cohen HL, Shaptro MA, Mandel FS, Shapiro ML. 1993. Normal ovaries in neonates and infants: 160(3):583-586. DOI 10.2214/ajr.160.3.8430559. Radiology 177(1):189-192. DOI 10.1148/radiology.177.1.2204964.

Darendeliler F, Aycan Z, Cetinkaya E, Vidilisan S, Bas F, Bideci A, Demirel F, Darcan S, hormone on growth, insulin resistance and related hormones (ghrelin, leptin and adiponectin) in Turner syndrome. Hormone research 68(1):1-7. DOI 10.1159/000098440

Coste J, Carel JC. 2012. Parental origin of the X-chromosome does not influence growth hormone

Study Group. 2016. X-chromosome gene dosage as a determinant of impaired pre and postnatal growth and adult height in Turner syndrome. European journal of endocrinology 174(3):281-288. DOI 10.1530/EJE-15-1000 
2006. The GH-IGF-IGFBP axis is changed in Turner syndrome: partial normalization by HRT. Growth hormone \& IGF research 16(5-6):332-339. DOI 10.1016/j.ghir.2006.09.001

Huang DX, Ma HD, Yang RZ, Yi SH, Liu YX, Hu QQ. 2015. Development of a 9-locus X-STR multiplex PCR system for genetic analysis of three ethnic populations in China. Journal of Huazhong University of Science and Technology. Medical sciences 35(2):183-187. DOI 10.1007/s11596-015-1408-3

Jung MK, Yu J, Lee JE, Kim SY, Kim HS, Yoo EG. 2020. Machine learning-based prediction of response to growth hormone treatment in Turner syndrome: the LG Growth Study. Journal of pediatric endocrinology \& metabolism 33(1):71-78. DOI 10.1515/jpem-2019-0311.PMID: 31811805

King KA, Makishima T, Zalewski CK, Bakalov VK, Griffith AJ, Bondy CA, Brewer CC. 2007. hearing 28(6): 831-841. DOI 10.1097/AUD.0b013e318157677f

Ko JM, Kim JM, Kim GH, Lee BH, Yoo HW. 2010. Influence of parental origin of the X chromosome on physical phenotypes and GH responsiveness of patients with Turner syndrome. Clinical endocrinology 73(1): 66-71. DOI 10.1111/j.1365-2265.2010.03782.x 2007. The influence of parental origin of $X$ chromosome genes on the stature of patients with $45 X$ Turner syndrome. Genetics and molecular research 6(1):1-7. 

e1. DOI 10.1016/j.jpeds.2019.04.056 1988. Effects of theophylline infusion on the growth hormone (GH) and prolactin response to GHreleasing hormone administration in acromegaly.Journal of endocrinological investigation 11(9):663-667. DOI: 10.1007/BF03350209

Morin A, Guimarey LM, Apezteguia M, Santucci ZC. 2009. Adult height in Turner Syndrome girls after long-term growth hormone treatment. Medicina 69(4):431-436.

Moka R, Sreelakshmi K, Gopinath PM, Satyamoorthy K. 2013. Cytogenetic evaluation of patients with clinical spectrum of Turner syndrome. Journal of human reproductive sciences 6(2):129-132. DOI 10.4103/0974-1208.117177

Menke LA, Sas TC, de Muinck Keizer-Schrama SM, Zandwijken GR, de Ridder MA, Odink

RJ, Jansen M, Delemarre-van de Waal HA, Stokvis-Brantsma WH, Waelkens JJ, Westerlaken

C, Reeser HM, van Trotsenburg AS, Gevers EF, van Buuren S, Dejonckere PH, Hokken-

Koelega AC, Otten BJ, Wit JM. 2010. Efficacy and safety of oxandrolone in growth hormonetreated girls with turner syndrome. The Journal of clinical endocrinology and metabolism 95(3):1151-1160. DOI 10.1210/jc.2009-1821

Noordman ID, van der Velden JA, Timmers HJ, Pienkowski C, Köhler B, Kempers M, Reisch

Grinten HL. 2019. Karyotype - Phenotype Associations in Patients with Turner Syndrome. 
Freriks K, Timmers H, van Alfen-van der Velden J. 2018. Phenotype in girls and women with Turner syndrome: Association between dysmorphic features, karyotype and cardio-aortic malformations. European journal of medical genetics 61(6):301-306. DOI 10.1016/j.ejmg.2018.01.004

Nathwani NC, Unwin R, Brook CG, Hindmarsh PC. 2000. Blood pressure and Turner syndrome. Clinical Endocrinology 52(3):363-370. DOI 10.1046/j.1365-2265.2000.00960.x.

Orsini LF, Salardi S, Pilu G, Bovicelli L, Cacciari E. 1984. Pelvic organs in premenarcheal girls: real-time ultrasonography. Radiology 153(1):113-116. DOI 10.1148/radiology.153.1.6473771. Familial Turner syndrome: the importance of information. Journal of pediatric endocrinology \& metabolism 29(5):617-620. DOI 10.1515/jpem-2015-0277

Pankowska E, Szalecki M, Romer TE. 2007. [Metabolic control and insulin administration in a girl with Turner syndrome and type 1 diabetes during long-term growth hormone therapy].Pediatric endocrinology, diabetes, and metabolism 13(4):213-215.

Ramachandram S, Keng WT, Ariffin R, Ganesan V. 2013. A mother with variant Turner 10.1007/s12041-013-0256-9 
410 of different pubertal stages. Clinical endocrinology 74(4):445-452. DOI 10.1111/j.1365-

$411 \quad 2265.2010 .03955 . x$

412 Spiliotis BE. 2008. Recombinant human growth hormone in the treatment of Turner syndrome.

413 Therapeutics and clinical risk management 4(6): 1177-1183. DOI 10.2147/tcrm.s1440

414 Scalco R, Trarbach E, Albuquerque EVA, Homma TK, Inoue-Lima TH, Nishi MY, Mendonca

415 BB, Jorge AAL. 2019. ESR1 polymorphism (rs2234693) influences femoral bone mass in patients

416 with Turner syndrome. Endocrine Connections 8(11):1513-1519. DOI 10.1530/EC-19-0398.

417 Salvarci A, Zamani A. 2018. Evaluation of sexual function and micro- testicular sperm extraction in

418 men with mosaic Turner syndrome. The National medical journal of India 31(5):274-278. DOI

$419 \quad$ 10.4103/0970-258X.261196.

Verver EJ, Freriks K, Sas TC, Huygen PL, Pennings RJ, Smeets DF, Hermus AR, Menke LA,

Wit JM, Otten BJ, van Alfen-van der Velden JA, de Muinck Keizer-Schrama SM, Topsakal V,

Admiraal RJ, Timmers HJ, Kunst HP. 2014. Karyotype-specific ear and hearing problems in

423 young adults with Turner syndrome and the effect of oxandrolone treatment. Otology\&neurotology

35(9):1577-1584. DOI 10.1097/MAO.0000000000000406

425

Verver EJ, Freriks K, Thomeer HG, Huygen PL, Pennings RJ, Alfen-van der Velden AA,

Timmers HJ, Otten BJ, Cremers CW, Kunst HP. 2011. Ear and hearing problems in relation to

karyotype in children with Turner syndrome. Hearing research 275(1-2):81-88. DOI

10.1016/j.heares.2010.12.007

Wasniewska M, Aversa T, Mazzanti L, Guarneri MP, Matarazzo P, De Luca F, Lombardo F,

Messina MF, Valenzise M. 2013. Adult height in girls with Turner syndrome treated from before 6 
431 years of age with a fixed per kilogram GH dose. European journal of endocrinology 169(4):439-443.

432

433

434

435

436

437

438

439

440

441

442

443

444

445

446

447

448

449

450

\section{4}

451 Supplemental Files DOI 10.1530/EJE-12-1032

Wu HH, Li H. 2019. Karyotype classification, clinical manifestations and outcome in 124 Turner syndrome patients in China. Annales d'endocrinologie 80(1):10-15. DOI 10.1016/j.ando.2017.10.011

Xu J, Wang J, Xuan S, Fang G, Tian J, Teng Y. 2018. The Effects of Childbirth Age on Maternal and Infant Outcomes in Pregnant Women. Iranian journal of public health 47(6):788-793.

Yeh T, Soto AG, Quintos JB, Topor LS. 2017. Turner syndrome and pituitary adenomas: a case report and review of literature. Journal of pediatric endocrinology \& metabolism 30(2):231-235. DOI 10.1515/jpem-2016-0202.PMID: 28099131

Zeng WH, Xu JJ, Jia MY, Ren YZ. 2014. Pseudohypoparathyroidism with Hashimoto's thyroiditis and Turner syndrome: a case report. Gynecological endocrinology 30(10):694-696. DOI $10.3109 / 09513590.2014 .929654$.

3

PeerJ reviewing PDF | (2020:11:55731:2:1:NEW 13 Sep 2021) 
452 Human Studies Approval.

453 Consent Form.

454 Raw Data. 


\section{Table 1 (on next page)}

Table 1. Demographic information of enrolled patients and general chromosome genotypes 
Table 1. Demographic information of enrolled patients and general chromosome genotypes

\begin{tabular}{|c|c|c|c|}
\hline Index & & Value or number & $\%$ \\
\hline Age (month) & & $90.90 \pm 28.99(44-154)$ & \\
\hline Weight $(\mathrm{kg})$ & & $20.69 \pm 5.10(12.60-36.50)$ & \\
\hline Height $(\mathrm{cm})$ & & $108.72 \pm 11.73(88.9-131.4)$ & \\
\hline Father's age when born & & $28.59 \pm 1.83(25-35)$ & \\
\hline Mother's age when born & & $26.74 \pm 1.80(23-31)$ & \\
\hline Father's height $(\mathrm{cm})$ & & $169.41 \pm 3.73(160-177)$ & \\
\hline Mother's height (cm) & & $157.59 \pm 3.07(152-165)$ & \\
\hline \multirow[t]{4}{*}{ Karyotyping } & Type 1 & 15 & $38.5 \%$ \\
\hline & Type 2 & 4 & $10.3 \%$ \\
\hline & Type 3 & 17 & $43.6 \%$ \\
\hline & Type 4 & 3 & $7.7 \%$ \\
\hline \multirow[t]{3}{*}{ Source of variation } & Father & 6 & $15.4 \%$ \\
\hline & Mother & 16 & $41.0 \%$ \\
\hline & Both & 17 & $43.6 \%$ \\
\hline
\end{tabular}

2 
Table 2 (on next page)

Table 2. Blood biochemical indicators of enrolled patients 
Table 2. Blood biochemical indicators of enrolled patients

\begin{tabular}{|c|c|c|c|c|c|}
\hline Index & $\mathbf{N}$ & Min & Max & Mean & SD \\
\hline GH excitation peak & 38 & 3.89 & 19.60 & 9.73 & 3.37 \\
\hline GH (IU/d/kg) & 39 & 1.5 & 2.0 & 1.54 & 0.13 \\
\hline ALT (U/L) & 39 & 6 & 43 & 15.72 & 6.82 \\
\hline AST (U/L) & 39 & 19 & 61 & 32.44 & 7.98 \\
\hline Total cholesterol (mmol/l) & 38 & 2.98 & 6.11 & 4.97 & 0.86 \\
\hline HDL (mmol/l) & 38 & 1.16 & 2.28 & 1.68 & 0.25 \\
\hline LDL (mmol/l) & 35 & 1.40 & 3.64 & 2.64 & 0.50 \\
\hline Insulin (pmol/l) & 39 & 3.02 & 112.00 & 39.60 & 27.67 \\
\hline Free T3 (pmol/1) & 39 & 4.46 & 9.10 & 6.16 & 0.92 \\
\hline Free T4 $(\mathrm{pmol} / \mathrm{l})$ & 39 & 11.06 & 26.77 & 13.67 & 2.58 \\
\hline Triiodothyronine (nmol/l) & 39 & 1.33 & 2.62 & 2.02 & 0.27 \\
\hline Thyroxine (nmol/l) & 38 & 87.88 & 140.64 & 112.27 & 11.31 \\
\hline TSH (uIU/ml) & 39 & 0.01 & 17.98 & 3.51 & 2.64 \\
\hline IGF-1 (ng/ml) & 38 & 36.7 & 375.0 & 144.09 & 71.90 \\
\hline IGFBP3 (ug/ml) & 39 & 1.76 & 5.11 & 3.55 & 0.89 \\
\hline LH (IU/L) & 39 & 0.10 & 25.20 & 0.83 & 4.01 \\
\hline FSH (IU/L) & 39 & 0.62 & 133.00 & 6.86 & 20.94 \\
\hline $\mathrm{E} 2(\mathrm{pmol} / \mathrm{l})$ & 39 & 73.0 & 277.0 & 84.26 & 33.06 \\
\hline Prolactin (mIU) & 39 & 110.00 & 772.74 & 357.89 & 132.71 \\
\hline Progesterone (nmol/l) & 39 & 0.19 & 2.01 & 0.72 & 0.42 \\
\hline HCG (mIU/ML) & 39 & 0.20 & 1.38 & 0.52 & 0.18 \\
\hline SHBG (nmol/1) & 39 & 28.00 & 109.00 & 59.75 & 22.82 \\
\hline
\end{tabular}

2 GH: growth hormone HDL: high density lipoprotein LDL: low density lipoprotein

3 TSH: thyroid-stimulating hormone LH: Luteinizing hormone FSH: Follicle-Stimulating Hormone

4 HCG: human chorionic gonadotropin SHBG: sex hormone binding globulin SD: Standard deviation 
Table 3 (on next page)

Table 3. The impact of $X$ origin on treatment effects 
Table 3. The impact of $X$ origin on treatment effects

\begin{tabular}{|c|c|c|c|c|c|c|c|c|}
\hline & \multicolumn{2}{|c|}{ Father } & \multicolumn{2}{|c|}{ Mother } & \multicolumn{2}{|c|}{ Both } & \multirow[t]{2}{*}{$\mathbf{F}$} & \multirow[t]{2}{*}{$\mathbf{p}$} \\
\hline & Mean & SD & Mean & SD & Mean & SD & & \\
\hline All samples & \multicolumn{2}{|c|}{$\mathrm{N}=6$} & \multicolumn{2}{|c|}{$N=16$} & \multicolumn{2}{|c|}{$\mathrm{N}=17$} & & \\
\hline \multicolumn{9}{|l|}{ Height } \\
\hline Baseline $(\mathrm{cm})$ & 103.02 & 7.43 & 110.92 & 12.20 & 108.65 & 12.36 & 0.991 & 0.381 \\
\hline Increase $(\mathrm{cm})$ & 8.00 & 0.00 & 8.24 & 1.53 & 6.25 & 1.26 & 10.693 & 0.000 \\
\hline \multicolumn{9}{|l|}{ IGF-1 } \\
\hline Baseline $(\mathrm{ng} / \mathrm{ml})$ & 127.50 & 49.31 & 157.17 & 90.86 & 137.24 & 57.81 & 0.483 & 0.621 \\
\hline 9-month (ng/ml) & 270.83 & 48.22 & 318.31 & 70.37 & 213.71 & 52.05 & 12.589 & 0.000 \\
\hline Age matched & \multicolumn{2}{|c|}{$\mathrm{N}=5$} & \multicolumn{2}{|c|}{$\mathrm{N}=10$} & \multicolumn{2}{|c|}{$\mathrm{N}=12$} & & \\
\hline \multicolumn{9}{|l|}{ Height } \\
\hline Baseline $(\mathrm{cm})$ & 104.28 & 7.56 & 103.76 & 9.06 & 106.38 & 8.10 & 0.291 & 0.750 \\
\hline Increase $(\mathrm{cm})$ & 8.00 & 0.00 & 8.31 & 1.24 & 6.56 & 1.31 & 6.744 & 0.005 \\
\hline \multicolumn{9}{|l|}{ IGF-1 } \\
\hline Baseline $(\mathrm{ng} / \mathrm{ml})$ & 137.40 & 48.01 & 104.77 & 45.26 & 127.52 & 35.60 & 1.295 & 0.292 \\
\hline 9-month (ng/ml) & 284.80 & 37.99 & 302.80 & 66.81 & 203.58 & 42.66 & 10.736 & 0.000 \\
\hline
\end{tabular}

2 SD: Standard deviation 
Table 4 (on next page)

Table 4. Association between mother's age and height when born on development and GH treatment 
Table 4. Association between mother's age and height when born on development and GH treatment

\begin{tabular}{lll}
\hline Factors & Spearman R & P value \\
\hline Association between mother's age when born and following factors & & \\
Uterine size (small/normal/large) & -0.442 & 0.005 \\
Prolactin (mIU) & -0.508 & 0.001 \\
Weight increase after treatment & -0.351 & 0.028 \\
Bone age difference after treatment & -0.353 & \\
\hline Association between mother's height when born and following factors & & 0.028 \\
Bone age difference (baseline) & -0.336 & 0.036 \\
IGF-1 level after treatment & 0.388 & 0.015 \\
\hline
\end{tabular}

2 